\title{
Emerging threats in addiction: will novel psychoactive substances contribute to exacerbating the ongoing drug overdose epidemic?
}

\author{
F. Scott Hall ${ }^{1} \cdot$ Klaus A. Miczek ${ }^{2,3}$ \\ Published online: 22 May 2019 \\ (C) Springer-Verlag GmbH Germany, part of Springer Nature 2019
}

One of the greatest concerns in the field of addiction (substance use disorders) has been the emergence of "new psychoactive substances" (NPS), referring to drugs whose widespread recreational or illicit use has only recently emerged as a public health problem. Indeed, the use of NPS has increased in recent years for each of the major classes of abused drugs, including opioids, cannabinoids, and stimulants (Graddy et al. 2018). One of the primary concerns about the widespread use of these drugs is that their properties are not fully understood, so that the degree of a threat that they pose for addiction, overdose, or other health consequences is uncertain. Initial evidence is based upon case reports at best, or hearsay at worst, but suggests that many of these drugs may present greater threats for abuse, addiction, adverse events, or overdose than the established drugs of abuse that they are replacing. The specter of a stimulant or cannabinoid version of fentanyl looms on the horizon, worrying public health officials, medical practitioners, and scientists alike. In some cases, the production of NPS is intended to bypass current restrictions by producing analogues with similar subjective effects that are not illegal (Baumann et al. 2014; Karila et al. 2015). In the case of cathinones (the $\beta$ ketone analogues of amphetamines), the emergence of these drugs has come in waves, with initial waves being made illegal by regulatory agencies only to be replaced by subsequent waves of alternative analogues with similar properties, but which are not yet regulated. This game

F. Scott Hall

frank.hall@utoledo.edu

1 Department of Pharmacology and Experimental Therapeutics, College of Pharmacy and Pharmaceutical Sciences, University of Toledo, Toledo, OH 43537, USA

2 Department of Psychology, Tufts University, Medford, MA 02155, USA

3 Departments of Neuroscience and Pharmacology, Tufts University School of Medicine, Boston, MA 02111, USA of regulatory "whack-a-mole" is exemplified by the progressive regulation of more and more cathinones by the United States Drug Enforcement Administration between 2011 and 2017 as new waves of these drugs emerged on illicit markets (Drug Enforcement Administration 2011, 2013, 2014, 2016, 2017). Although the US Federal Analogue Act (21 U.S.C. § 813 ) allows the scheduling of analogues based on their similarity to existing scheduled drugs, in practice this requires substantial information about substances which is often not available. It is difficult to establish several key properties of these drugs that would make them fall under such regulation: What really constitutes an analogue? How do we establish abuse or addictive potential? How do the properties of these drugs compare to already scheduled drugs? (for discussion of these issues see King et al. (2014))

It is worth noting that the widespread emergence of NPS has coincided with a widespread increase in the abuse of opioid drugs, in the USA and elsewhere, and consequent overdoses from these drugs in epidemic proportions. Although the origins and ultimate causes of this epidemic are quite complex, the initial phase began with very widespread use of opioid analgesics, resulting in a first phase characterized by increasing numbers of overdoses involving prescription opioids during the 1990s (Centers for Disease Control and Prevention 2012). The second phase began with a shift towards a greater number of heroin overdoses (Rudd et al. 2014). This shift was the result of many factors, including greater emphasis on preventing licit and illicit access to prescription opioids, consequently increasing the street price of these drugs, along with an influx of inexpensive high-purity heroin to the USA. The third phase, which we are still experiencing, involved the substitution of illicitly manufactured fentanyl and fentanyl analogues for heroin (Peterson et al. 2016). These phases of the opioid epidemic are represented in Fig. 1. Among other trends, it is quite clear that as of 2017, overdoses from fentanyl and fentanyl analogues were still increasing at an alarming rate. The danger of these opioids is not surprising given their much greater potency (Volpe et al. 2011). It should be clear 
10

\section{Waves of the Rise in Opioid Overdose Deaths}

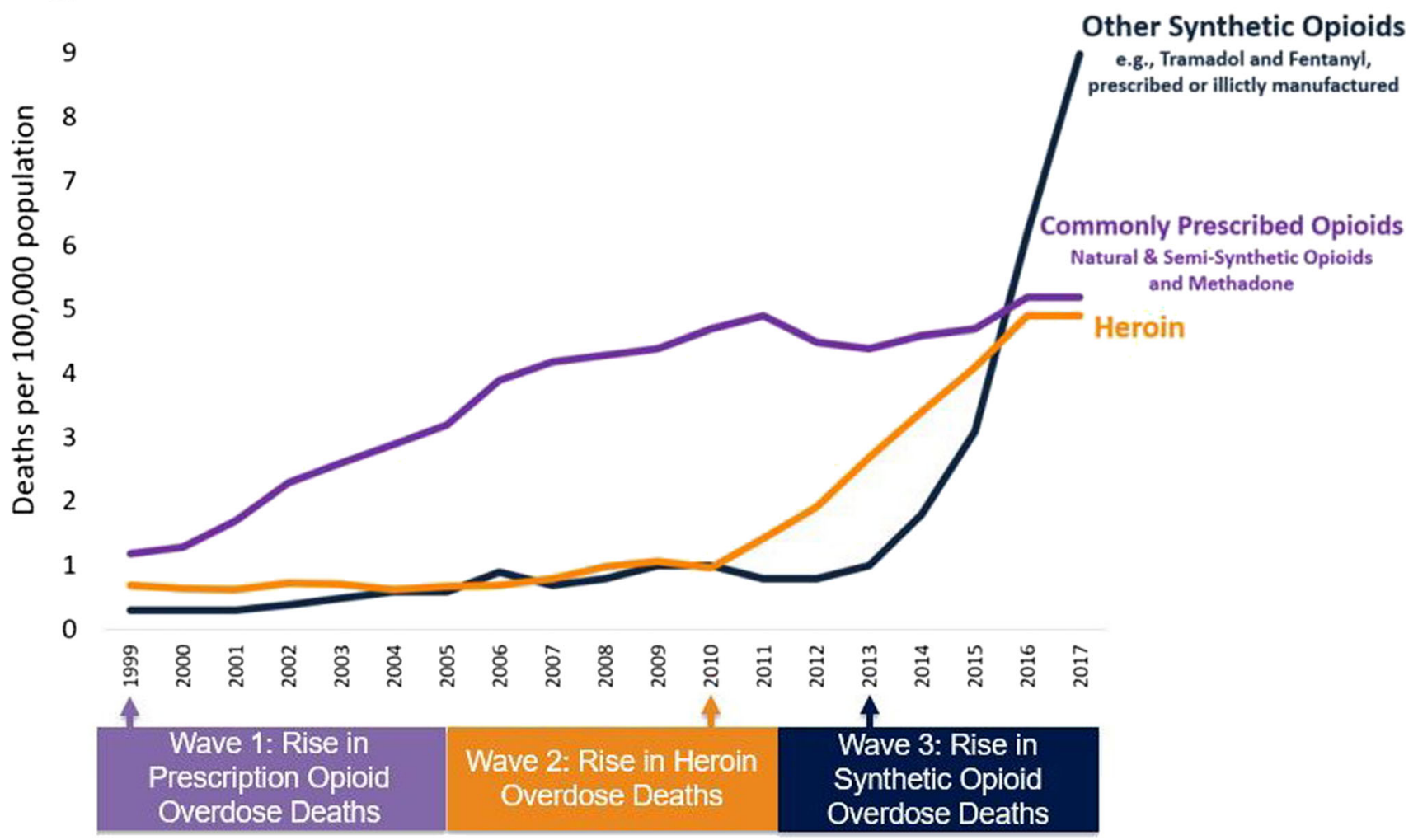

SOURCE: National Vital Statistics System Mortality File.

Fig. 1 Representation of yearly overdose rates between 1999 and 2017 from prescription opioids (purple), heroin (yellow), and fentanyl and other synthetic opioids (blue), constituting the three waves of the opioid

here that the transition to high-potency opioid analogues was less a matter of supply than demand. Users take these highly potent opioids to produce the same effects as the less potent ones, and the more potent the drug the greater its attraction among many users, despite the dangers, although greater risks do discourage some use (Ciccarone et al. 2017). Various opioids are sold on the street as "heroin," which to some extent has become a generic term among users for drugs with opiodergic effects. Indeed, Ciccarone et al. (2017) note that users may have difficulty discriminating the "type of heroin" (e.g., heroin, fentanyl, some other fentanyl analogue, or some mixture). This uncertainly alone, as well as varying purity of illicit drugs, also contributes to the likelihood of overdose. Another factor that may also contribute to the increased sale of fentanyl and fentanyl derivatives may be from the distribution side. Most of these drugs are imported to the USA from abroad; their increased potency also means that a smaller volume (for the same number of sales units) needs to be imported compared to heroin.

Given these considerations, an important question would be where the drug epidemic is going next. As is clear in Fig. 2 (from drugabuse.gov), the next phase in this epidemic is epidemic that are defined on the $x$-axis (reprinted from https://www.cdc. gov/drugoverdose/epidemic/index.html)

already in progress: there was a notable increase in stimulant overdoses, both for cocaine and other stimulants such as methamphetamine, in 2016 and 2017. Moreover, this may not just reflect increased use of stimulants, but also the much more dangerous practice of combining stimulant and opioid use. One study found large increases in combined observation of positive results for opioids and stimulants between 2013 and 2018 in samples from several medical settings (LaRue et al. 2019). Combined fentanyl and cocaine positive results increased from $0.9 \%$ in 2013 to $17.6 \%$ in 2018. Combined fentanyl and methamphetamine positive results increased from $0.9 \%$ in 2013 to $7.9 \%$ in 2018 . This suggests that the combined use of these drugs is likely to constitute the next phase in the drug epidemic. Indeed, at least one analysis has suggested that the upward trend in cocaine overdoses is associated with combined use with opioids (McCall Jones et al. 2017). Although focus is starting to shift to the somewhat familiar combination of stimulants and opioids, the combination of stimulants with the highly potent fentanyl is a new problem. This development should be considered in a wider context as well-it reflects not just the combination of two illicit drugs to produce a more desired combined effect, but 


\section{US National Drug Overdose Deaths, 1999-2017}

50,000

40,000

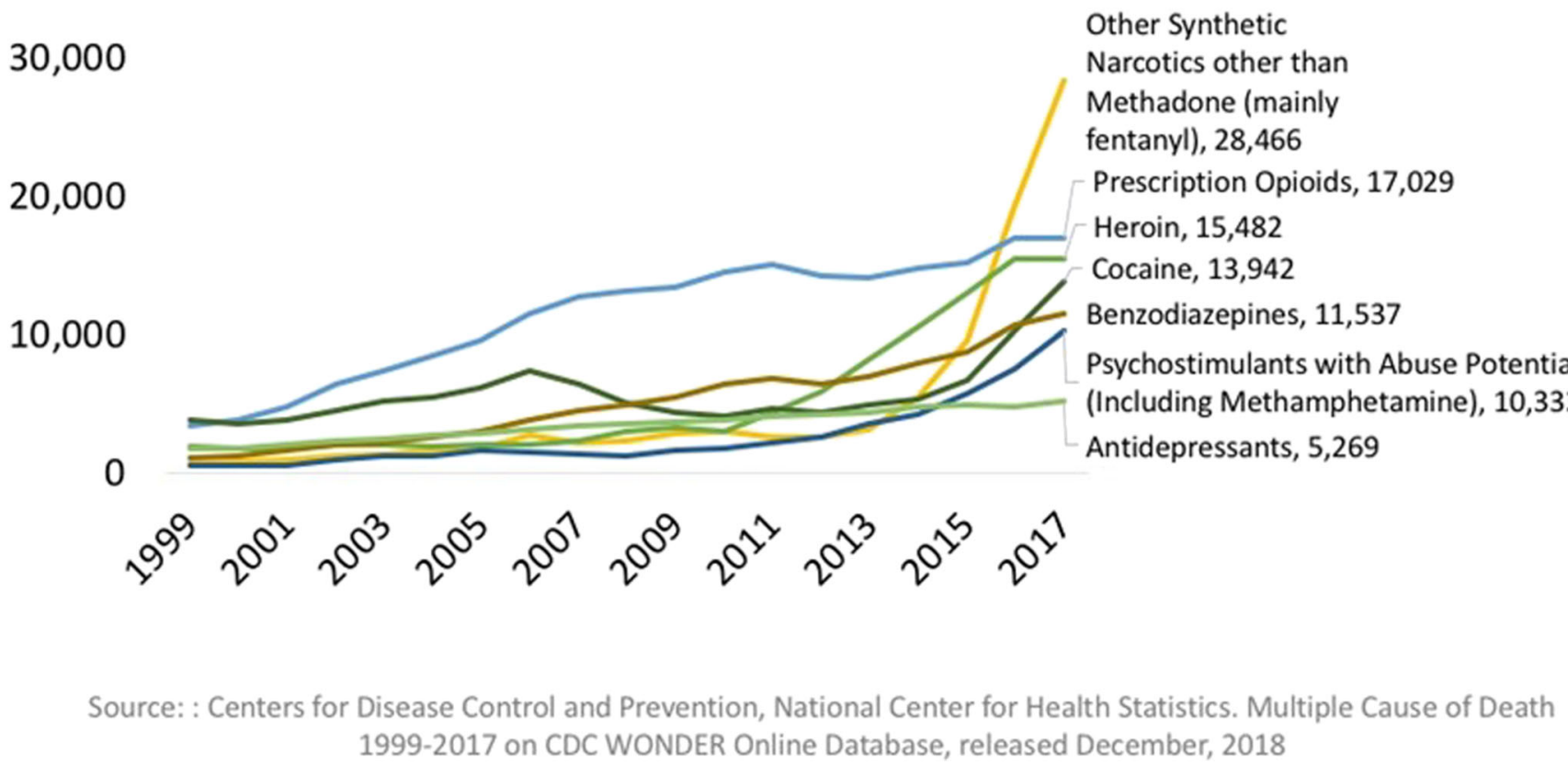

Fig. 2 Representation of yearly overdose rates between 1999 and 2017 from opioids and other substances. In 2016 and 2017 , there was a notable uptick in overdoses from cocaine and other stimulants (reprinted from https:/www.drugabuse.gov/related-topics/trends-statistics/overdose-death-rates)

also the inclusion of a highly potent analogue in this drug combination. The emergence of highly potent analogues of other drugs, including many of the cathinones (Baumann et al. 2013; Gannon et al. 2018), may lead to similar public health concerns as these drugs become more widely used. Indeed, they may already be more widely used than is currently appreciated.

One of the problems that arose with the widespread use of fentanyl and fentanyl analogues was that many users did not initially know that they were using these drugs. The same is true of many of the cathinones, which have effects similar to those of methamphetamine, methylenedioxymethamphetamine (MDMA), or cocaine. Indeed, studies have found that many users that thought they were using "MDMA/ecstasy/molly" tested positive for various cathinones (Palamar et al. 2017; Palamar et al. 2016). These studies, as well as the previous discussion about fentanyl/heroin, clearly indicate that drug users do not always know the exact drug that they are taking, and are willing, or actively seek, to combine drugs to produce desired effects.
Local drug suppliers may also combine drugs in a market competition for clientele-without disclosing the "special ingredients" to users of course. These factors may contribute to the likelihood of overdose as a high proportion of drug overdose cases involve ingestion of multiple drugs, as exemplified by the case of mephedrone (Papaseit et al. 2017), although the problem is far from new (Coffin et al. 2003).

\section{Contributions to this special issue}

The potential for NPS to exacerbate the ongoing drug overdose epidemic, even beyond the current catastrophic levels, gives even more impetus to the study of these emerging drugs. The present volume focusses on one class of these drugs, synthetic cathinones. This is a diverse class of drugs with effects similar to established illicit psychostimulant drugs, but little research had been devoted to their study until recent years. 
This issue begins with a review by Bonson et al. that addresses the difficulties that have emerged as authorities have sought to regulate these drugs, and the considerations for the regulatory process illustrated by the recent history of these regulatory efforts. As a more specific example of these types of difficult decisions, Gauvin et al. provide a response to a previous article calling for the regulation of "Kratom" (containing the novel opioid mitragynine). Decisions about the regulation of drugs for their abuse/addictive potential are of course determined by our understanding of their abuse potential, therapeutic potential, and potential for adverse outcomes. For illicit drugs, this often begins with clinical observations of adverse effects. An article by Ameline et al. considers the problem of identifying a lethal dose of 3 methylmethcathinone based on clinical observations. As noted above, one of the ways in which the drug epidemic may continue to worsen is through the combined use of illicit drugs, particularly stimulants and opioids. Oliver et al. contribute a report that is directly relevant to this issue, on the adulteration of other illegal drugs with cathinones.

Mechanistic studies of cathinones will tell us much about their potential for various physiological effects. Sprague and colleagues review how modifications of the core cathinone structures affect the pharmacokinetic properties of cathinone analogues. Several reports published here investigate the properties of cathinones that might underlie their behavioral effects, including their ability to increase extracellular monoamine levels (articles by Marusich, Blough, Eshleman, Baumann, and their colleagues), including relative actions at the three main monoamine neurotransmitters, as well as the relative effects on monoamine reuptake and release. Several other reports included here address other aspects of cathinone actions, including the effects of cathinone drug combinations (Megarbane et al.), regulation of dopamine transporter levels (Pubill et al.), interactions of the related compound 2aminoindane, and its analogues, with $\alpha 2$ adrenergic receptors as well as monoamine transporters (Halberstadt et al.), and the attributes of cathinones that may contribute to their discriminative stimulus effects (Baker et al.). To complete this section, a review by Eltit and colleagues reviews a new approach to profiling the effects of amphetamines and cathinones on monoamine transporters using calcium biosensors.

Understanding the actions of cathinones and their risk for abuse and addiction liability requires behavioral studies of their reinforcing properties. This topic is initially considered here in a review by Lopez-Rodriguez and colleagues that focusses upon drug-drug interactions, continuing the theme of polydrug use and abuse in this volume. Several original investigations (articles by Walker, Collins, Erwin, Negus, and their colleagues) report on the reinforcing effects of cathinones as examined through several different approaches to this topic. An important aspect of these studies is the potential of many cathinones to have greater reinforcing effects than other psychostimulant drugs such as amphetamine and cocaine. A final original report on the behavioral effects of cathinones (Nelson et al.) addresses the potential of cathinones to induce aversive effects, as determined by conditioned taste aversion. The relative rewarding/aversive potential of these drugs is another factor that will influence their potential for abuse (Verendeev and Riley 2012).

Amphetamines, including both methamphetamine and MDMA, have long been known to have the potential to induce monoamine neurotoxicity (for review see Carvalho et al. (2012)). Surprisingly, it has been suggested that many cathinones may be less likely to induce such effects (for discussion see Angoa-Perez et al. (2017)). This topic is further explored in this volume in a review by Olive and colleagues, that specifically addresses the potential role of inflammatory processes in adverse responses to cathinones, including cognitive impairment. Two original studies (by Kuhn, Murnane, and colleagues) further examine the roles that other factors may have in the potential for cathinone-induced neurotoxicity.

\section{Conclusions}

The articles included in this collection will contribute to filling the large gaps in our knowledge about the potential of synthetic cathinones for abuse, addiction, and various adverse outcomes. This knowledge is important because the use of these drugs continues to rise, even as their diversity expands. Moreover, it is clear from use and overdose data trends characterizing the ongoing epidemic of drug overdoses that stimulant drugs, and co-use of stimulant and opioid drugs, are initiating the next phase of this epidemic (Wave 4). Moreover, just as increases in the use of high-potency opioid agonists (e.g., fentanyl and fentanyl analogues) have greatly exacerbated this epidemic, there is the potential for higher potency stimulant drugs, including higher potency cathinones analogues, to similarly contribute to an exacerbation of the epidemic.

\section{References}

Angoa-Perez M, Anneken JH, Kuhn DM (2017) Neurotoxicology of synthetic cathinone analogs. Curr Top Behav Neurosci 32:209-230

Baumann MH, Partilla JS, Lehner KR, Thorndike EB, Hoffman AF, Holy M, Rothman RB, Goldberg SR, Lupica CR, Sitte HH, Brandt SD, Tella SR, Cozzi NV, Schindler CW (2013) Powerful cocaine-like actions of 3,4-methylenedioxypyrovalerone (MDPV), a principal constituent of psychoactive 'bath salts' products. Neuropsychopharmacology 38:552-562

Baumann MH, Solis E Jr, Watterson LR, Marusich JA, Fantegrossi WE, Wiley JL (2014) Baths salts, spice, and related designer drugs: the science behind the headlines. J Neurosci 34:15150-15158 
Carvalho M, Carmo H, Costa VM, Capela JP, Pontes H, Remiao F, Carvalho F, Bastos Mde L (2012) Toxicity of amphetamines: an update. Arch Toxicol 86:1167-1231

Centers for Disease Control and Prevention (2012) CDC grand rounds: prescription drug overdoses - a U.S. epidemic. MMWR Morb Mortal Wkly Rep 61:10-13

Ciccarone D, Ondocsin J, Mars SG (2017) Heroin uncertainties: exploring users' perceptions of fentanyl-adulterated and -substituted 'heroin'. Int J Drug Policy 46:146-155

Coffin PO, Galea S, Ahern J, Leon AC, Vlahov D, Tardiff K (2003) Opioids, cocaine and alcohol combinations in accidental drug overdose deaths in New York City, 1990-98. Addiction 98:739-747

Drug Enforcement Administration (2011) Schedules of controlled substances: temporary placement of three synthetic cathinones into schedule I. Fed Regist 76:65371-65375

Drug Enforcement Administration (2013) Establishment of drug codes for 26 substances. Fed Regist 78:664-666

Drug Enforcement Administration (2014) Schedules of controlled substances: temporary placement of 10 synthetic cathinones into schedule I. Fed Regist 79:12938-12943

Drug Enforcement Administration (2016) Schedules of controlled substances: extension of temporary placement of 10 synthetic cathinones in schedule I of the controlled substances act. Fed Regist 81:11429-11431

Drug Enforcement Administration (2017) Schedules of controlled substances: placement of 10 synthetic cathinones into schedule I. Fed Regist 82:12171-12177

Gannon BM, Baumann MH, Walther D, Jimenez-Morigosa C, Sulima A, Rice KC, Collins GT (2018) The abuse-related effects of pyrrolidine-containing cathinones are related to their potency and selectivity to inhibit the dopamine transporter. Neuropsychopharmacology 43:2399-2407

Graddy R, Buresh ME, Rastegar DA (2018) New and emerging illicit psychoactive substances. Med Clin North Am 102:697-714

Karila L, Megarbane B, Cottencin O, Lejoyeux M (2015) Synthetic cathinones: a new public health problem. Curr Neuropharmacol 13:12-20

King LA, Ujvary I, Brandt SD (2014) Drug laws and the 'derivative' problem. Drug Test Anal 6:879-883

LaRue L, Twillman RK, Dawson E, Whitley P, Frasco MA, Huskey A, Guevara MG (2019) Rate of fentanyl positivity among urine drug test results positive for cocaine or methamphetamine. JAMA Netw Open 2:e192851
McCall Jones C, Baldwin GT, Compton WM (2017) Recent increases in cocaine-related overdose deaths and the role of opioids. Am J Public Health 107:430-432

Palamar JJ, Salomone A, Gerace E, Di Corcia D, Vincenti M, Cleland CM (2017) Hair testing to assess both known and unknown use of drugs amongst ecstasy users in the electronic dance music scene. Int J Drug Policy 48:91-98

Palamar JJ, Salomone A, Vincenti M, Cleland CM (2016) Detection of "bath salts" and other novel psychoactive substances in hair samples of ecstasy/MDMA/“Molly" users. Drug Alcohol Depend 161:200205

Papaseit E, Olesti E, de la Torre R, Torrens M, Farre M (2017) Mephedrone concentrations in cases of clinical intoxication. Curr Pharm Des 23:5511-5522

Peterson AB, Gladden RM, Delcher C, Spies E, Garcia-Williams A, Wang Y, Halpin J, Zibbell J, McCarty CL, DeFiore-Hyrmer J, DiOrio M, Goldberger BA (2016) Increases in fentanyl-related overdose deaths - Florida and Ohio, 2013-2015. MMWR Morb Mortal Wkly Rep 65:844-849

Rudd RA, Paulozzi LJ, Bauer MJ, Burleson RW, Carlson RE, Dao D, Davis JW, Dudek J, Eichler BA, Fernandes JC, Fondario A, Gabella B, Hume B, Huntamer T, Kariisa M, Largo TW, Miles J, Newmyer A, Nitcheva D, Perez BE, Proescholdbell SK, Sabel JC, Skiba J, Slavova S, Stone K, Tharp JM, Wendling T, Wright D, Zehner AM, Centers for Disease C, Prevention (2014) Increases in heroin overdose deaths - 28 States, 2010 to 2012. MMWR Morb Mortal Wkly Rep 63:849-854

Verendeev A, Riley AL (2012) Conditioned taste aversion and drugs of abuse: history and interpretation. Neurosci Biobehav Rev 36:21932205

Volpe DA, McMahon Tobin GA, Mellon RD, Katki AG, Parker RJ, Colatsky T, Kropp TJ, Verbois SL (2011) Uniform assessment and ranking of opioid mu receptor binding constants for selected opioid drugs. Regul Toxicol Pharmacol 59:385-390

Publisher's note Springer Nature remains neutral with regard to jurisdictional claims in published maps and institutional affiliations. 